\title{
Synthetic Antimicrobial Peptides: III-Effect of Cationic Groups of Lysine, Arginine, and Histidine on Antimicrobial Activity of Peptides with a Linear Type of Amphipathicity
}

\author{
N. V. Amirkhanov ${ }^{a, 1}$, A. V. Bardasheva ${ }^{a}$, N. V. Tikunova ${ }^{a}$, and D. V. Pyshnyi ${ }^{a}$ \\ ${ }^{a}$ Institute of Chemical Biology and Fundamental Medicine, Siberian Branch, Russian Academy of Sciences, \\ Novosibirsk, 630090 Russia \\ Received July 4, 2020; revised July 16, 2020; accepted July 18, 2020
}

\begin{abstract}
We have studied the antimicrobial and hemolytic activity of synthetic antimicrobial peptides (SAMPs), i.e., $\mathrm{Arg}_{9} \mathrm{Phe}_{2}$ (P1-Arg), $\mathrm{Lys}_{9} \mathrm{Phe}_{2}$ (P2-Lys), and $\mathrm{His}_{9} \mathrm{Phe}_{2}$ (P3-His), which have a "linear" type of amphipathicity and contain the cationic amino acid residues of arginine, lysine, or histidine. In this study, we have used various pathogenic microorganism strains of gram-negative bacteria (Pseudomonas aeruginosa, Escherichia coli, and Salmonella enterica), gram-positive bacteria (Staphylococcus aureus), and the conditionally pathogenic yeast fungus (Candida albicans). It has been shown that the replacement of the arginine residues by lysine or histidine residues in the tested SAMPs significantly degrades their antibacterial properties in the series: P1-Arg $>$ P2-Lys $\gg$ P3-His. The cationic analog of SAMP, P1-Arg, has the highest antibacterial activity $\left(\mathrm{MIC}_{50}=43-76 \mu \mathrm{M}\right)$, while peptide P3-His does not exhibit this activity $\left(\mathrm{MIC}_{50}>100 \mu \mathrm{M}\right)$. The P1-Arg and P2-Lys peptides were 6-10 times more active against the opportunistic fungus $C$. albicans $\left(\mathrm{MIC}_{50} 6.7\right.$ and $10.9 \mu \mathrm{M}$, respectively) and the P3-His peptide has 100-times increased antimycotic activity $\left(\mathrm{MIC}_{50} 0.6 \mu \mathrm{M}\right)$ compared with their effect on bacterial cells. All of the tested peptides with the linear type of amphipathicity and low hydrophobicity, i.e., P1-Arg, P2-Lys, and P3-His, that contain only two Phe residues regardless of the presence of cationic amino acids (Arg, Lys, or His) exhibit a relatively low hemolytic activity (not more than $4 \%$ hemolysis at $1000 \mu \mathrm{M}$ peptide concentration). Thus, considering the same synthesis efficiency (56-63\%) and approximately the same low toxicity of the tested SAMPs with a linear type of amphipathicity, it is recommended to use those that contain the cationic arginine or histidine residues to create antibacterial or antifungal peptide agents, respectively.
\end{abstract}

Keywords: solid-phase peptide synthesis, synthetic antimicrobial peptides, amphiphilicity, linear type of amphipathicity, circular type of amphipathicity, hemolytic activity, selectivity, Candida albicans, Staphylococcus aureus, histatins

DOI: $10.1134 / \mathrm{S} 106816202103002 \mathrm{X}$

\section{INTRODUCTION}

Antimicrobial peptides (AMP) are the most numerous and well-studied class of biologically active peptides, which are synthesized in response to contact with foreign microorganisms [1-3]. Although only a few AMPs have found application in medical practice,

\footnotetext{
Abbreviations: AMPs, antimicrobial peptides; CTA, circle type of amphipathicity; LAT, "linear" type of amphipathicity; MHC, minimal hemolytic concertation (the peptide concentration that causes the lysis of no more than $10 \%$ of fresh red blood cells); $\mathrm{MIC}_{50}$, minimal inhibitory concentration (the peptide concentration that causes $50 \%$ inhibition of the microorganism growth); SAMPs, synthetic antimicrobial peptides; Fmoc, 9-fluorenylmethoxycarbonyl; HATU, 2-(1H-7-azabenzotriazol-1-yl)-1,1,3,3-tetramethyluronium hexafluorophosphate; Hst, histidine; NMM, $N$-methylmorpholine; Pbf, 2,2,4,6,7pentamethyldihudrobenzofuran-5-sulfonyl; PBS, phosphate buffered saline; TFA, trifluoroacetic acid.

${ }^{1}$ Corresponding author: phone: +7 (383) 363-51-35; e-mail: nariman@niboch.nsc.ru.
}

the study of this class of compounds continues to attract the attention of researchers in the world [2-9]. The increased attention to AMPs is caused by the development of resistant microorganisms, especially bacteria, which makes the design of new antibiotics based on antimicrobial peptides very attractive [5-7, 10-12].

Previously, we proposed the use of synthetic antimicrobial peptides (SAMPS) to design and search for AMPs with new properties [13,14]. The structures of the SAMPs differ from that of the numerous wellknown native AMPs [2, 8, 9]. The design of these SAMPs is based on the general principles of the effect of AMPs on microbial cells, i.e., on the principles of the peptide amphiphilicity, which is the presence of both hydrophobic and hydrophilic positively charged groups in the peptide molecule. Depending on the relative spatial location of the polar amphiphilic amino acids in AMPs, these peptides can be divided into two 
(a) Hydrophilic back
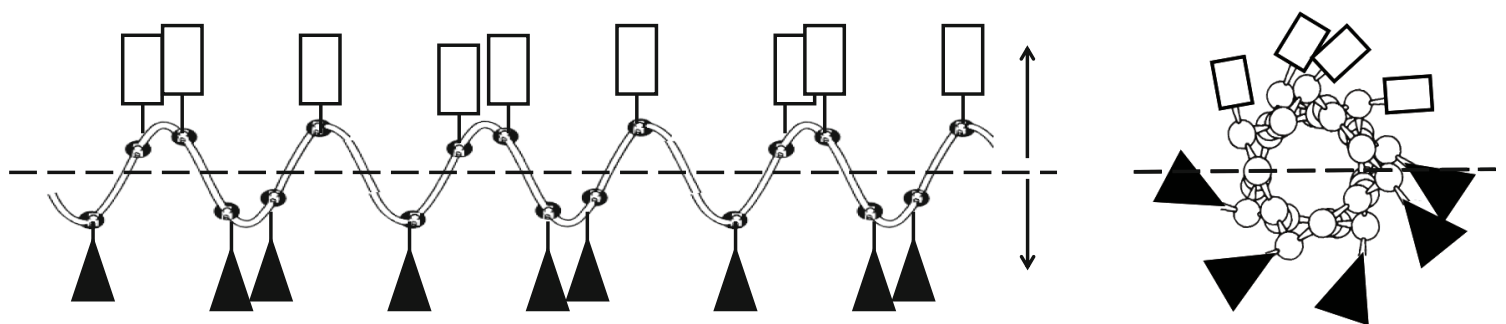

Hydrophobic tummy
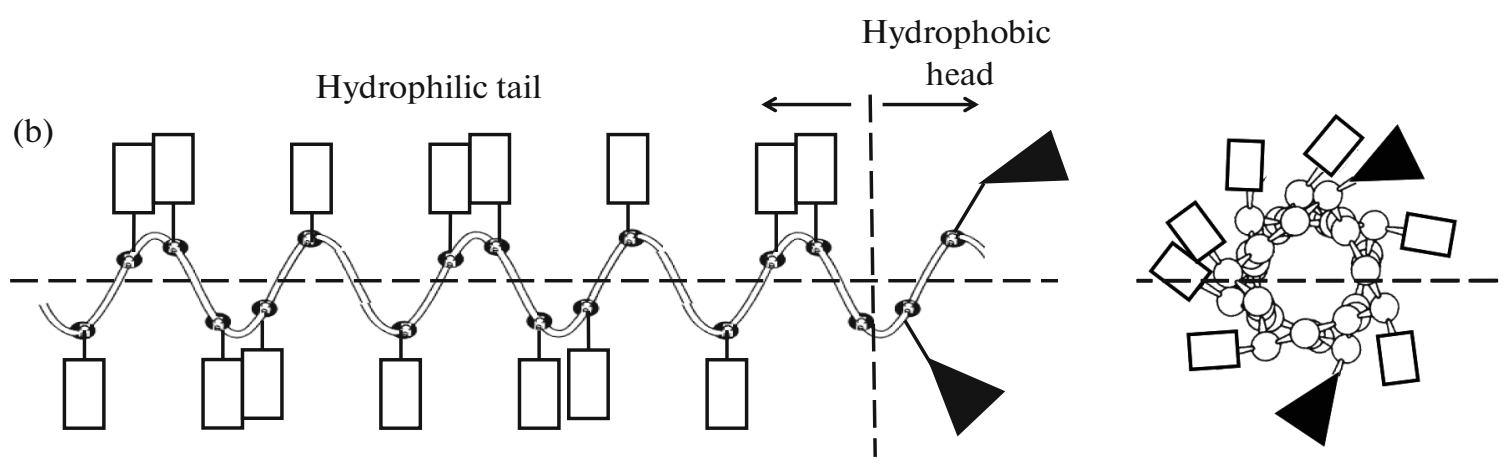

Fig. 1. A hypothetical representation of the classical circular (a) and linear (b) types of amphipathicity of $\alpha$-helical peptides. Rectangles and triangles indicate hydrophilic cationic and hydrophobic amino acid residues, respectively. In the case of the circle type of amphipathicity (CTA) [2, 8, 9], the hydrophobic and hydrophilic polar surfaces of the $\alpha$-helical peptide molecule are separated by the longitudinal centerline (a); in this case, the upper surface is hydrophilic and the bottom surface is hydrophobic (a backtummy type of amphipathicity). In the case of the linear type of amphipathicity (LTA), the hydrophobic and hydrophilic (cationic) amino acid residues are located at the opposite ends along the peptide axis and separated by a transverse line perpendicular to the longitudinal axis of the peptide (b); in this case, the left part of the molecule is a hydrophilic tail and the right part is a hydrophobic head. Two-dimensional projections of the spiral wheels of Schiffer and Edmundson [15, 16] of the same peptides are presented on the right $[15,16]$. The projection of the linear type of amphipathicity $(b)$ on the left indicates the higher polar homogeneity of hydrophobic and hydrophilic groups than the presentation of the same molecule in the classical form of two-dimensional projections of spiral wheels (right).

subtypes according to the type of their amphipathicity, i.e., the classic circular type of amphipathicity (CTA) (Fig. 1a) $[2,8,9,15,16]$ and the new linear type of amphipathicity (LTA) (Fig. 1b) [13, 14].

In the above works, it was shown that SAMPs with the linear type of amphipathicity (LTA-SAMPs) have increased antimicrobial properties compared to those with the classical circular type of amphipathicity (CTA-SAMPs). Compared to the CTA peptides that contain amphiphilic hydrophobic and/or hydrophilic cationic groups on the opposite sides of the $\alpha$-helix, the LTA peptides are less hydrophobic and, thereby, exhibit less hemolytic activity, which significantly increases the selectivity index of these SAMPs [13, 14].

Earlier, we studied the biological activity of these peptides based on the arginine-containing cationic peptide $\mathrm{R}_{9} \mathrm{~F}_{2}$ (P1-Arg) [13, 14]. However, some questions remained unanswered. First, is the previously revealed increased antimicrobial activity of LTASAMP, P1-Arg (compared to CTA-SAMPs [13, 14]) caused by the presence of the cationic arginine residues $\left(\mathrm{p} K_{\mathrm{a}} \sim 12\right)$, or, can the same effect be exhibited in the presence of other cationic residues, such as lysine $\left(\mathrm{p} K_{\mathrm{a}} \sim 10\right)$, and/or conditionally cationic residues, such as histidine $(\mathrm{pKa} \sim 6)$ ? Second, is there a difference in the efficiency of the synthesis of the arginine-, lysine-, or histidine-containing peptides, which can be caused by the chemical properties of these residues and protecting groups of the side chains? If the efficiency of the synthesis of the peptides does not depend on their cationic composition and their antimicrobial activity does not differ from each other, the advantage in choosing an effective antimicrobial drug can be given to those peptides that have less hemolytic activity or toxicity. Therefore, third, it was necessary to find out whether the hemolytic activity of LTA-SAMPs depends on their cationic composition (the presence of the arginine, lysine, or histidine residues).

In general, the peptide should be recognized as a prospective antimicrobial drug if it has a high selectivity index (or therapeutic index, TI), i.e., the high MHC value and the low $\mathrm{MIC}_{50}$ value $(\mathrm{TI}=$

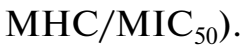

We studied three types of SAMPs with a linear type of amphipathicity of the general structure $\mathrm{X}_{9} \mathrm{Phe}_{2}$, where $X=A r g$, Lys, or His to optimize the peptide 
structure and search for the most active antimicrobial agents. The goal of this work was to study the dependence of the synthesis efficiency of the SAMPs with the linear type of amphipathicity on the content of the cationic amino acid components (arginine, lysine, or histidine) and to assess their antimicrobial and hemolytic activity.

\section{RESULTS AND DISCUSSION}

Synthesis of the P1-Arg, P2-Lys, and P3-His peptides. The peptide synthesis was carried out by the standard solid-phase method using the Fmoc strategy [17] according to Scheme 1 on a PS3 peptide synthesizer, which was previously adapted for large-scale preparative synthesis in the reactor version [18, 19]. The synthesized P1-Arg, P2-Lys, and P3-His pep- tides were the 11-meric amino acid sequences that contained the $N$-terminal amino group, which impaired an additional positive charge to the peptide, and the amide group at the $C$-end, which neutralized the negative charge of the terminal carboxyl group (Scheme 1). The efficiency of the addition of one amino acid unit, which was evaluated by the deprotection of the Fmoc group at each stage, was 96.9-99.8\% for the P1-Arg, P2-Lys, and P3-His peptides (Table 1). The final yields of the peptides after 11 steps of condensation, deprotection, removal from the polymer carrier, and purification by RP-HPLC were 56-63\%. According to HPLC and MS data, all the isolated peptides corresponded to the expected structure and were homogeneous with the content of the main substance of at least $95 \%$ (Table 1).

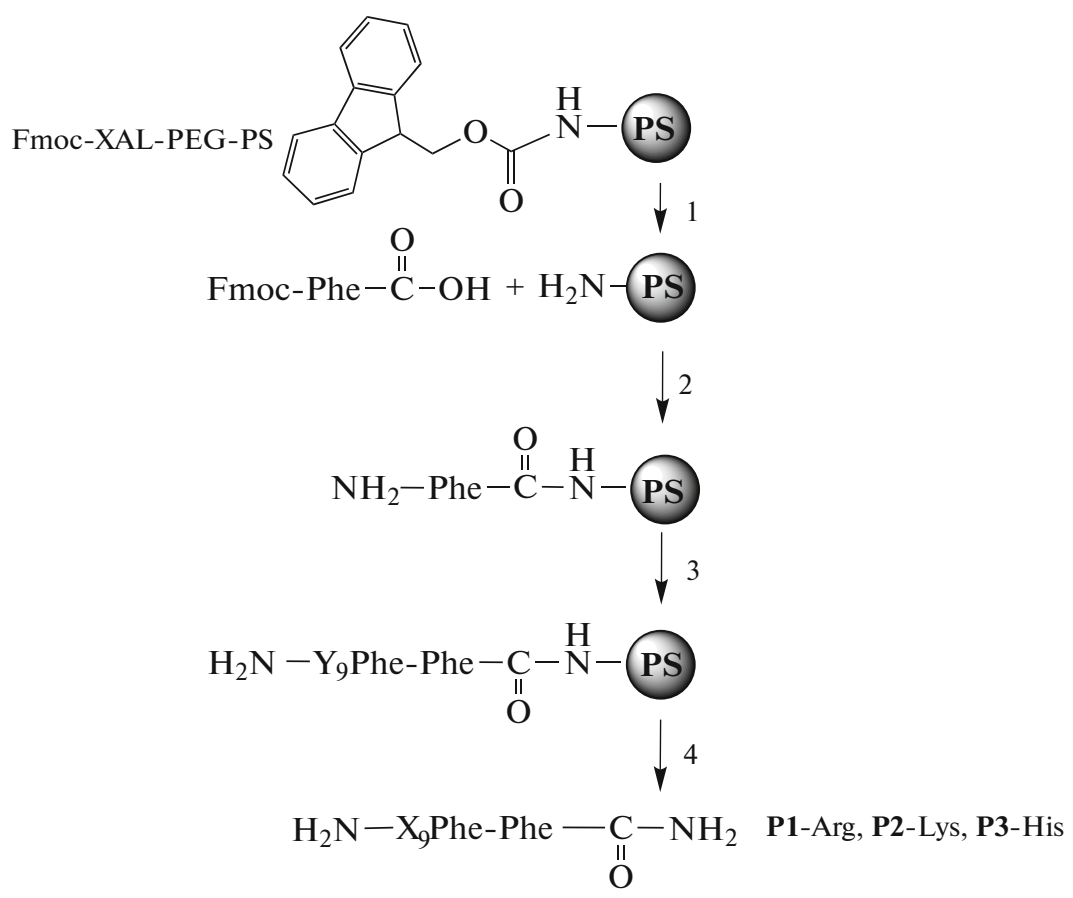

Scheme 1. Synthesis of peptides P1-Arg, P2-Lys, and P3-His with the $C$-terminal amide groups by the solid-phase Fmoc strategy. $\mathrm{Y}=\mathrm{Arg}^{\mathrm{Pbf}}$, Lys ${ }^{\mathrm{Boc}}$, or His, respectively; $\mathrm{X}=\mathrm{Arg}$, Lys, or His; PS is polystyrene polymer; 1 . piperidine/ DMF (1 : 5). 2. (a) HATU. NMM. DMF; (b) Ac 2 O/NMM/DMF; (c) piperidine/DMF (1 : 5); 3. Repeating cycles:

(a) Fmoc-Phe-OH, Fmoc-Arg ${ }^{\mathrm{Pbf}}-\mathrm{OH}$, Fmoc-Lys ${ }^{\mathrm{Boc}}-\mathrm{OH}$ or Fmoc-His-OH, HATU, NMM, DMF;

(b) $\mathrm{Ac}_{2} \mathrm{O} / \mathrm{NMM} / \mathrm{DMF}$; (c) piperidine/DMF (1: 5); 4. TFA/m-cresol.

Thus, the synthesis of the P1-Arg, P2-Lys, and P3His peptides in the mode used is quite efficient with relatively high yields, regardless of the composition of the amino acids.

The main problem in the peptide synthesis may be deprotection of the products, removal from the polymer carrier, and purification of the crude reaction mixture. Impurities in the products, i.e., modified or shorter peptides, can appear because of insufficient condensation efficiency or modification of the amino acid residues during the synthesis and deprotection. Some shorter peptides may differ little from the target product in terms of mobility during HPLC. The efficiency of the addition of monomer units was quite high for all of the tested peptides (Table 1). The yield, which was evaluated by the Fmoc deprotection at each stage, was especially high for the histidine-containing peptide, P3-His, and averaged $99.8 \%$ at each stage. The total yield for this peptide was $98.2 \%$ (Table 1). However, the yield of P3-His based on the HPLC 
Table 1. Structures, yields, and physicochemical properties of synthetic antimicrobial peptides used in this work

\begin{tabular}{|c|c|c|c|c|c|c|c|c|c|}
\hline \multirow{3}{*}{ Peptide } & \multirow{3}{*}{ Structure $^{\mathrm{a}}$} & \multicolumn{2}{|c|}{ Yield, by Fmoc ${ }^{\mathrm{b}}, \%$} & \multirow{3}{*}{$\begin{array}{c}\text { Yield by } \\
\text { HPLC }^{\mathrm{c}}, \%\end{array}$} & \multirow{3}{*}{$\begin{array}{c}\text { Total } \\
\text { yield }^{\mathrm{d}}, \%\end{array}$} & \multicolumn{2}{|c|}{ Retention time ${ }^{\mathrm{e}}, \min$} & \multirow{2}{*}{\multicolumn{2}{|c|}{$\begin{array}{c}\text { Molecular } \\
\text { weight }[M+\mathrm{H}]\end{array}$}} \\
\hline & & \multirow[b]{2}{*}{ average } & \multirow[b]{2}{*}{ total } & & & & & & \\
\hline & & & & & & $\begin{array}{c}80 \% \\
\mathrm{CH}_{3} \mathrm{CN}\end{array}$ & $\begin{array}{c}50 \% \\
\mathrm{CH}_{3} \mathrm{CN}\end{array}$ & calc. & exp. \\
\hline P1-Arg & $\mathrm{H}-\mathrm{R}_{9} \mathrm{~F}_{2}-\mathrm{NH}_{2}$ & 96.9 & 70.2 & 85.0 & 56.0 & 15.5 & 20.4 & 1717.0 & 1716.5 \\
\hline P2-Lys & $\mathrm{H}-\mathrm{K}_{9} \mathrm{~F}_{2}-\mathrm{NH}_{2}$ & 97.5 & 75.5 & 80.0 & 57.8 & 14.6 & 18.2 & 1465.0 & 1465.3 \\
\hline P3-His & $\mathrm{H}-\mathrm{H}_{9} \mathrm{~F}_{2}-\mathrm{NH}_{2}$ & 99.8 & 98.2 & 70.5 & 62.9 & 15.6 & 20.0 & 1545.7 & 1545.8 \\
\hline
\end{tabular}

${ }^{\mathrm{a}}$ The length of all peptides is the same (11 aa). The charge is +10 for all peptides. ${ }^{\mathrm{b}}$ The yields of condensation on the polymer support were evaluated by the Fmoc deprotection after each stage (average yield) and last stage (total yield). ${ }^{\circ}$ The yield was evaluated by the

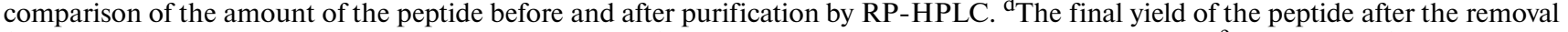
from the polymer support and RP-HPLC based on the first loaded amino acid on the polymer support. ${ }^{\mathrm{e}}$ Conditions of chromatography, see Experimental.

analysis was lowest compared with that for the P1-Arg and P2-Lys peptides (Fig. 2). This can be explained by the fact that the activation and following attachment of the monomer histidine units is accompanied by the formation of some side products, which most likely affects the purity of the target compound before its isolation and purification by RP-HPLC. Despite the difference in the intermediate yields of the three peptides, the final yields of the purified target products P1-Arg, P2-Lys, and P3-His were approximately the same $(56,58$, and $63 \%$, respectively). Most likely, the inefficiency of the RP-HPLC purification of the P3His peptide is compensated by the high condensation efficiency of the amino acid units (Table 1).

Thus, the efficiency of the synthesis of the P1-Arg, P2-Lys, and P3-His peptides is nearly independent of the composition of the cationic amino acids, i.e., arginine, lysine, or histidine.

Antimicrobial activity of the P1-Arg, P2-Lys, and P3-His peptides. To study the antimicrobial activity of the P1-Arg, P2-Lys, and P3-His peptides, we used gram-negative bacteria (Pseudomonas aeruginosa, Escherichia coli, and Salmonella enterica), gram-positive bacteria (Staphylococcus aureus), and the opportunistic yeast fungus (Candida albicans).

Each of the peptides at the final concentrations of $0.3-100 \mu \mathrm{M}$ was added to growing cultures of the microbial cells. The effect of the peptides on the cell growth was monitored by the optical absorption at $595 \mathrm{~nm}$ of the suspension of the culture medium for $24 \mathrm{~h}$. The quantification of the antimicrobial activity of the peptides was evaluated by two dose-dependent curves, which were 1) the dependence of the relative growth degree of microbe cultures $\left(N_{\mathrm{p}} / N_{0}\right)$ and 2) the dependence of the relative growth inhibition degree of the same cultures $\left(1-N_{\mathrm{p}} / N_{0}\right)$ on the peptide concentration. $N_{\mathrm{p}}$ and $N_{0}$ are the optical absorption values (concentrations) of microbial particles after the addition of the peptide and in the control culture, respectively (Fig. 3). The intersection of these two curves indicates the minimal inhibitory concentration of the peptide $\left(\mathrm{MIC}_{50}, \mu \mathrm{M}\right)$, which causes $50 \%$ inhibition of microorganism growth after incubation for $24 \mathrm{~h}$ at $37^{\circ} \mathrm{C}$. As an example, Fig. 3 shows the dependence of the growth degree and growth inhibition degree of C. albicans on the concentration of the P1-Arg, P2-Lys, and P3-His peptides in the medium. Similar graphs were obtained for the other tested cell cultures (data not shown), which allowed us to evaluate the corresponding average $\mathrm{MIC}_{50}$ values for all peptides used in this work (Table 2).

Peptide P1-Arg exhibited maximal activity against the bacterial cultures (Table 2). Peptide P3-His was not active against bacteria in the concentration range of up to $100 \mu \mathrm{M}$. Peptide P2-Lys had the activity against two bacterial cultures, i.e., E. coli and P. aeruginosa $\left(\mathrm{MIC}_{50}=77.5\right.$ and $80.0 \mu \mathrm{M}$, respectively).

Thus, the replacement of the arginine residues in the previously studied $\mathrm{H}-\mathrm{R}_{9} \mathrm{~F}_{2}-\mathrm{NH}_{2}$ peptide by the lysine residues did not increase the antibacterial activity. The histidine analog of this peptide even lost any noticeable antibacterial activity (Table 2).

The different effect of the P1-Arg, P2-Lys, and P3His peptides was observed on the opportunistic fungus Candida albicans (Fig. 3, Table 2). The effectiveness of these peptides on C. albicans cell cultures was on average 6-10 times higher than that on bacterial cells. It should be noted that the effect of P3-His on C. albicans was higher not only in comparison with its effect on bacterial cells but also in comparison with the effect of the P1-Arg and P2-Lys peptides on the same cell culture. Peptide P3-His was the most active against C. albicans $\left(\mathrm{MIC}_{50}=0.6 \mu \mathrm{M}\right)$ compared to P1-Arg and P2-Lys $\left(\mathrm{MIC}_{50}=6.7\right.$ and $10.9 \mu \mathrm{M}$, respectively) (Table 2), i.e., antimicrobial activity of P3-His against C. albicans was 10 times higher than that of P1-Arg and P2-Lys. At the same time, the fungicidal activity of P3-His exceeded its antibacterial activity by a factor of more than 100 (Table 2).

This unique action of the P3-His peptide against fungal cultures is confirmed by the literature data, which indicate a whole class of histidine-containing 

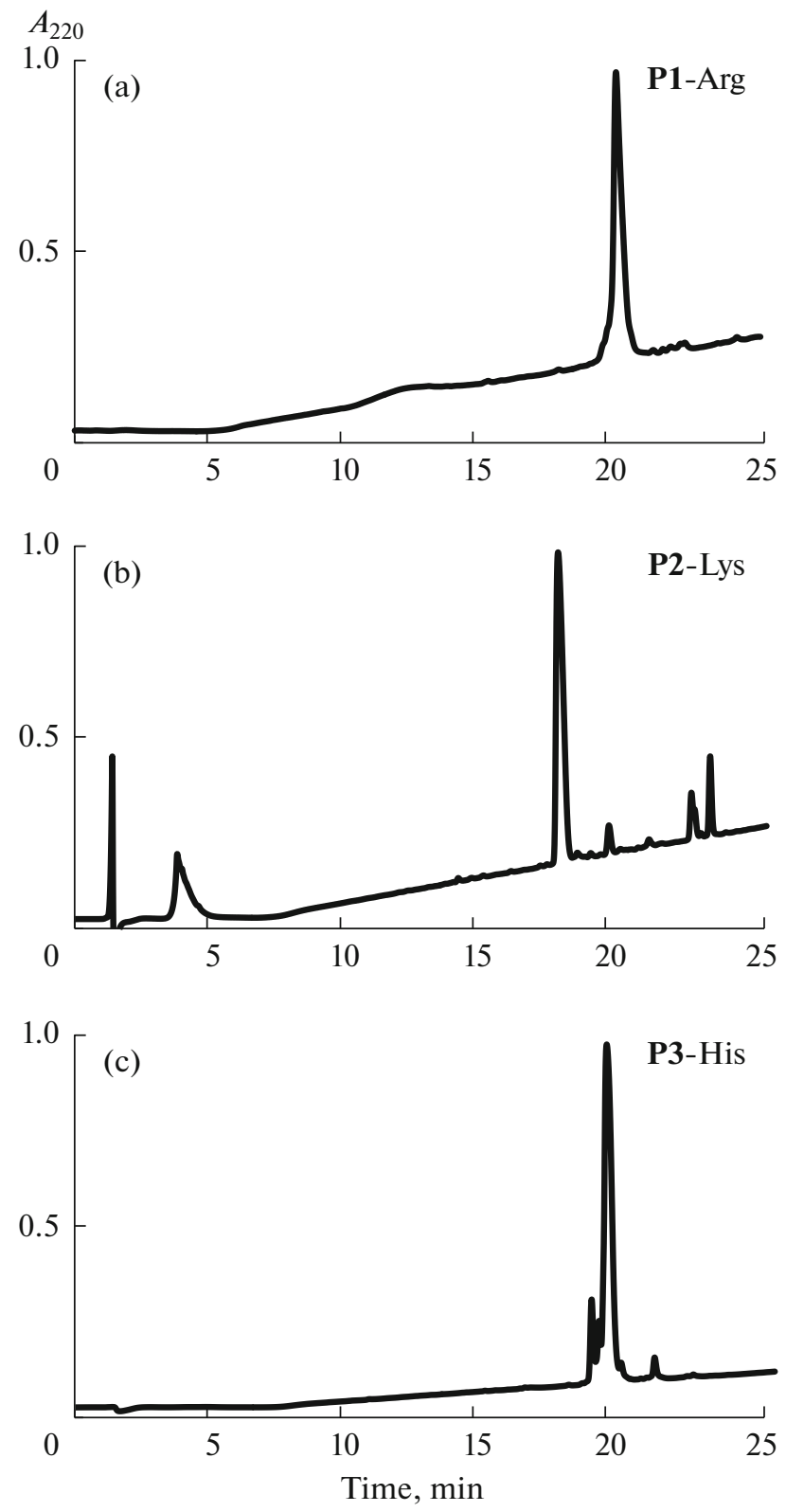

Fig. 2. RP-HPLC profiles of reaction mixtures of peptides P1-Arg (a), P2-Lys (b), and P3-His (c) after the synthesis, deprotection, and removal from the polymer support. The products were detected at $220 \mathrm{~nm}$. Conditions of chromatography see in Experimental.

natural AMPs, so-called histatins (Hst). These histidine-rich (cationic) antimicrobial proteins are contained in saliva and show selective activity against both conditionally pathogenic yeast cultures, such as C. albicans [20], and other yeast cultures [21]. For example, it is known that Hst-5, has the strongest fungicidal effect against pathogenic fungi including not only C. albicans [22] but also other medically important Candida species, such as Candida kefyr, Candida krusei, and Candida parapsilosis $\left(\mathrm{MIC}_{50}=3-7 \mu \mathrm{M}\right.$ ), as well as Cryptococcus neoformans and Aspergillus
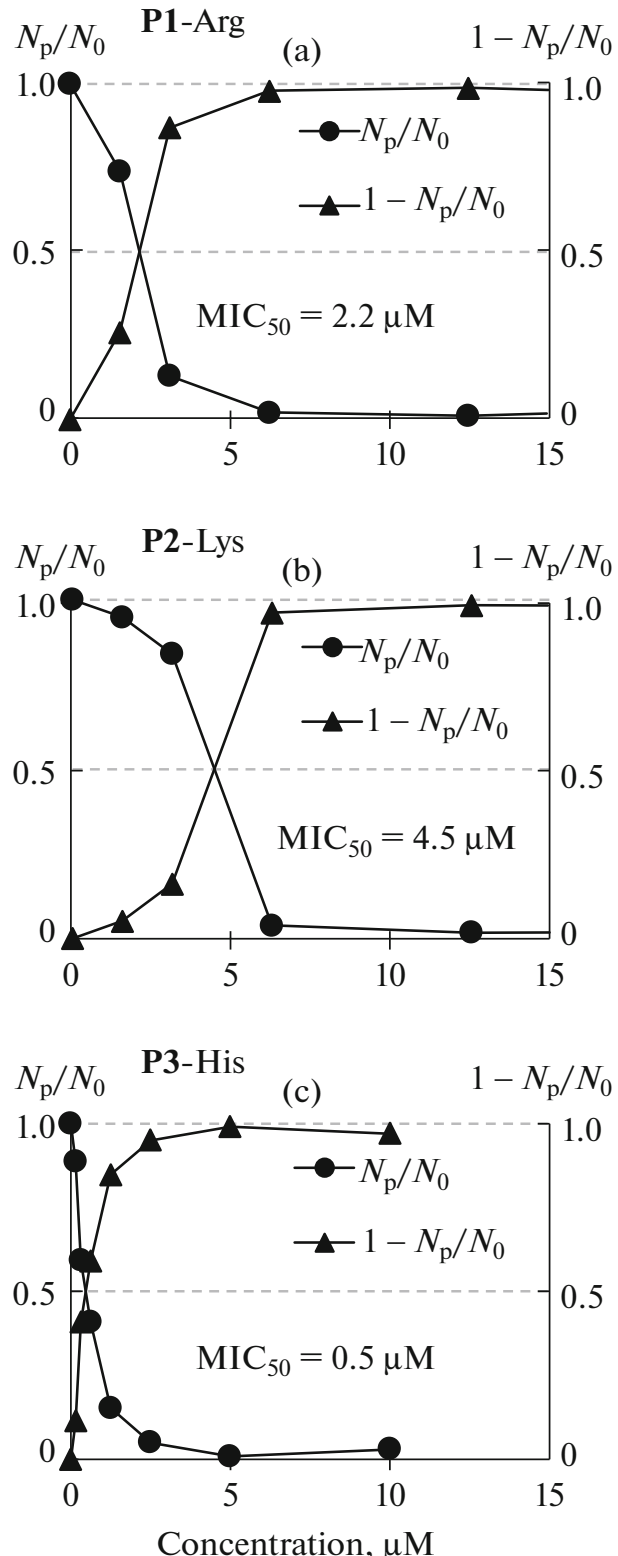

Fig. 3. Dependence of the relative growth degree $\left(N_{\mathrm{p}} / N_{0}\right)$ and growth inhibition degree $\left(1-N_{\mathrm{p}} / N_{0}\right)$ of C. albicans on the concentration of the P1-Arg (a), P2-Lys (b), and P3His (c) peptides after incubation for $24 \mathrm{~h} . N_{\mathrm{p}} / N_{0}$ is the ratio of the optical absorption (concentration) of the microbial particles after the addition of the peptide preparation to that in the control culture.

fumigatus $\left(\mathrm{MIC}_{50}=1.5-2.0 \mu \mathrm{M}\right)$ [23]. It is also known that Hst-5 can inhibit the transformation of almost $100 \%$ of $C$. albicans cells into more pathogenic hyphae $[24,25]$.

The antimicrobial activity of histatins makes them part of the innate immune system [26]. Histatins (Hst-1, Hst-3, and Hst-5) were first isolated in 1988 as peptides, which were involved in maintaining oral homeostasis and binding metal ions [20, 22]. Earlier studies have pointed to membranolytic action for Hst, which 
Table 2. Antimicrobial activity of peptides P1-Arg, P2-Lys, and P3-His

\begin{tabular}{l|c|c|c|r|r}
\hline \multirow{2}{*}{\multicolumn{1}{c|}{ Peptides }} & \multicolumn{5}{|c}{ MIC $_{50}, \mu \mathrm{M}$} \\
\cline { 2 - 6 } & Candida albicans & $\begin{array}{c}\text { Staphylococcus } \\
\text { aureus }\end{array}$ & Escherichia coli & Salmonella enterica & $\begin{array}{c}\text { Pseudomonas } \\
\text { aeruginosa }\end{array}$ \\
\hline P1-Arg & 6.7 & 42.8 & 48.2 & 59.4 & 76.0 \\
P2-Lys & 10.9 & $>100.0$ & 77.5 & 100.0 & 80.0 \\
P3-His & 0.6 & $>100.0$ & $>100.0$ & $>100.0$ & $>100.0$ \\
AgNO $_{3}{ }^{\text {a }}$ & 48.0 & 26.6 & 18.6 & 22.2 & 22.1 \\
Chlorhexidine $^{\text {a }}$ & 9.7 & 1.8 & 1.7 & 7.7 & 9.4 \\
\hline
\end{tabular}

${ }^{a}$ Aqueous solution of silver nitrate [14] and chlorhexidine were used as the internal controls to compare the relative antimicrobial activity of the peptides.

causes fungal cell death. However, recent studies have shown that more likely sites of Hst exposure are multiple intracellular targets, i.e., the mode of Hst action is more metabolic than membranolytic. For example, it is known that Hst-5, once inside fungal cells, can affect the functioning of mitochondria and lead to oxidative stress, and the ultimate cause of cell death can be an imbalance of ions because of the osmotic stress [27]. In addition to these diverse actions on intracellular targets, the pathways based on the ability of histatins to bind to copper and/or zinc metal ions are also discussed.

The metabolic pathway of AMP exposure to microbial cells is more effective than the membranolytic pathway because the former allows the initiation of a cascade of processes, which lead to an indirect violation of the normal metabolism of cells and, ultimately, to cell death. The membranolytic pathway of AMP exposure to microbial cells is direct and "mechanistic" in a certain sense, i.e., AMP acts only on the cell membrane, which leads to its destruction. The membranolytic process requires a larger number of peptide molecules. These reasons probably explain the increased fungicidal activity of the tested P3-His peptide, which exhibits metabolic action, like many other histidine-containing AMPs. Its fungicidal activity was more than 10 times higher compared to the P1-Arg and P2-Lys peptides, which are characterized predominantly by the membranolytic effect, like many other cationic AMPs. Moreover, we assume that the activity of P3-His against $C$. albicans exceeds its activity against the tested bacterial cells because the yeast cells contain specific receptors on their surface to histidine-rich peptides.

According to the literature data (e.g., the review [27] and the references therein), Hst-5 binds to the cell wall proteins of $C$. albicans (Ssa1/2) and glycans and is absorbed by cells through fungal polyamine carriers. Once inside fungal cells, Hst-5 can affect the mitochondrial function and cause oxidative stress. However, the ultimate cause of cell death is volume dysregulation and ion imbalance because of osmotic stress.
Since not only Hst-5 but also other histatins have specific activity against $C$. albicans, we can assume that there are specific receptors for histidine-rich peptides on the surface of $C$. albicans yeast cells.

The reason for the penetration of histatines, as we assume, is not their cationic composition (the histidine-containing P3-His peptide has one positive charge due to the terminal amino group and a weak positive charge due to histidine residues) but the presence of microbial receptors specific to histidine-rich peptides. In this case, penetration of the peptides into the cell most likely should occur not through an electrostatic but a receptor-mediated mode. However, the electrostatic interaction also plays an important role in the initial binding to the negatively charged cell surface of C. albicans.

Hemolytic activity. SAMPs as potential drugs should meet the following criteria: high efficiency of their synthesis, an enhanced antimicrobial activity, and relatively low toxicity to higher organisms, particularly low hemolytic activity. In most works concerning the design of modified natural AMPs, scientists were able to reduce their hemolytic activity by changing the protein structure, whereas attempts to increase the antimicrobial activity of the modified AMPs did not always lead to the desired result $[6,25,26]$. Probably, nature has already chosen the optimal structure of the corresponding AMPs. Nevertheless, a decrease in the hemolytic activity of the modified natural AMP, even while maintaining its previous antimicrobial activity, led in some cases to a significant (up to 50fold) increase in the selectivity index of this AMP [6]. When hemolysis does not exceed $10 \%$ at $100-125 \mu \mathrm{M}$ concentration of the peptide in the medium, the index of hemolytic activity is considered acceptable $[6,11$, 12]. It should be noted that a decrease in hemolytic activity was generally achieved by a decrease in the total hydrophobicity of the modified natural AMPs by replacing hydrophobic amino acid residues with any neutral, hydrophilic, or cationic amino acid residues. In some cases, this replacement significantly reduced 


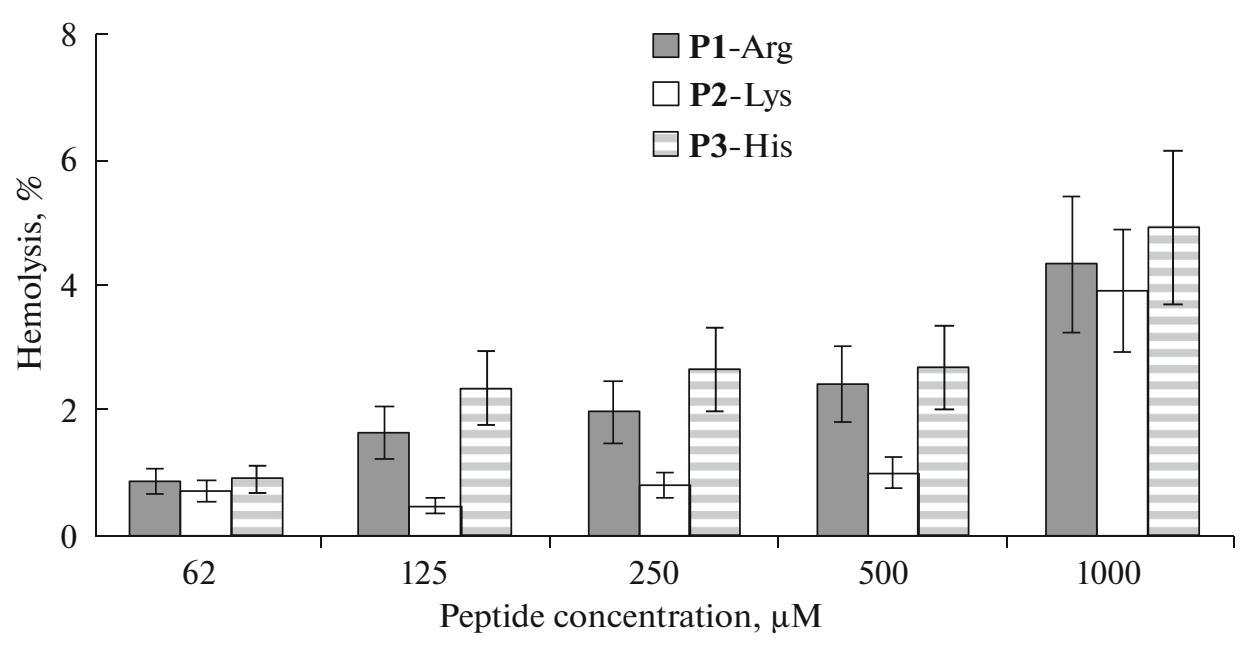

Fig. 4. Hemolytic activity of peptides P1-Arg, P2-Lys, P3-His.

their hemolytic activity but had no noticeable effect on their antimicrobial activity [11, 12].

The results of the concentration dependence of the hemolytic activity of peptides P1-Arg, P2-Lys, and P3-His are shown in Fig 4. The hemolytic activity of these peptides did not exceed $4 \%$ even at a rather high concentration (up to $1000 \mu \mathrm{M}$ ) in the erythrocytecontaining medium. This value is a relatively low hemolytic activity index in comparison with the literature data known for natural AMPs $(10 \%$ at $100-125 \mu \mathrm{M})$ $[6,11,12]$.

Thus, the hemolytic activity of peptides P1-Arg, P2-Lys, and P3-His is low and differs little from each other (within $2-4 \%$ at the same $100-1000 \mu \mathrm{M}$ concentration of peptides) regardless of their cationic amino acid composition.

Nevertheless, some insignificant differences should be noted between the hemolytic properties of the P1-Arg, P2-Lys, and P3-His peptides. The hydrophobicity of peptides P1-Arg, P2-Lys, and P3-His should be approximately the same due to the same number of hydrophobic (two Phe) and hydrophilic cationic (nine Arg, Lys, or His) residues in their structures (Table 1). Therefore, no difference should be expected in the hemolytic properties between the tested peptides. However, as mentioned above, hydrophobicity of the arginine- and histidine-containing peptides, which was evaluated by their retention time during the RP-HPLC analysis (Table 1), appeared to be slightly higher than that of the lysine-containing peptide. We found that the hemolytic properties of the tested peptides change proportionally to their hydrophobic properties. The arginine- and histidine-containing peptides exhibited a similar hemolytic activity (2.4 and $2.7 \%$, respectively), which was higher than the hemolytic activity of the Lys-containing peptide (1\%) at the same peptide concentration of $500 \mu \mathrm{M}$ (Fig. 4).
Thus, according to their hemolytic activity and hydrophobicity of the tested peptides, they can be arranged as P3-His $>$ P1-Arg $>$ P2-Lys.

\section{EXPERIMENTAL}

Reactants. We used reagents for the peptide synthesis from Sigma, Fisher Scientific, Bachem, and Protein Technologies (United States); polystyrene polymer 855013 Novabiochem ${ }^{\circledR}$ NovaSyn ${ }^{\circledR} T G$ Sieber resin functionalized by 9-Fmoc-aminoxanten-3yloxyl fragment $(200 \mathrm{mmol} / \mathrm{g}$, Merck Schuchardt OHG, Germany); protected amino acid monomers (Protein Technologies, United States); condensing agent HATU, i.e., 2-(1H-7-azabenzotriazol-1-yl)1,1,3,3-tetramethyluronium hexafluorophosphate (Cat. No. 023926, Oakwood Products, United States).

Peptide synthesis. The peptides were synthesized by solid-phase Fmoc strategy [17] according to Scheme 1 on a peptide PS3 synthesizer (Protein Technologies, United States), which was adopted for the preparative synthesis in the reactor variant $[18,19]$. The content of the target compound in the synthesized peptides was at least $95 \%$ according to RP-HPLC data.

Strains of microorganisms. The strains of gramnegative bacteria (Pseudomonas aeruginosa, Escherichia coli, and Salmonella enterica), gram-positive bacteria (Staphylococcus aureus), and the conditionally pathogenic yeast fungus (Candida albicans) were produced and maintained in the Collections of Extremophilic Microorganisms and Type Cultures (Institute of Chemical Biology and Fundamental Medicine, Siberian Branch, Russian Academy of Sciences).

Analytical RP-HPLC was performed on an LC-20 AD chromatograph (Shimadzu, Japan) using an SPD-M20A detector (Shimadzu, Japan) on a Gemini column $(5 \mu \mathrm{m} \mathrm{NX}-\mathrm{C} 18,110 \AA$ A, $4.6 \times 250 \mathrm{~mm}$ (Phe- 
nomenex, United States). The column was equilibrated by $0.1 \%$ TFA, and the chromatography was carried out in a linear gradient of acetonitrile concentration $(0-80 \%)$ for $30 \mathrm{~min}$ at a flow rate of $1 \mathrm{~mL} / \mathrm{min}$. The products were detected at 210, 220, 240, and $260 \mathrm{~nm}$.

Molecular masses of the peptides (Table 1) were evaluated on a REFLEX III MALDI-TOF spectrometer (Bruker Daltonics, Germany) and an LC/MS XCT Ultra ESI-MS spectrometer (Agilent Technologies, United States) in the Center of MassSpectrometric Analysis (Institute of Chemical Biology and Fundamental Medicine, Siberian Branch, Russian Academy of Sciences).

Preparation of the peptide solutions for biochemical studies. The peptide solutions of a certain concentration were prepared using dry samples immediately before the experiment. The concentrations of the P1-Arg, P2-Lys, and P3-His peptides that contained two phenylalanine residues were additionally evaluated by measuring the optical absorption in the near-UV region of the spectrum. The molar absorption coefficients at $260 \mathrm{~nm}\left(330 \mathrm{~L} \mathrm{~mol}^{-1} \mathrm{~cm}^{-1}\right)$ were previously determined in the solutions prepared from dry samples of the peptides. The peptide solutions for the evaluation of antimicrobial activity were prepare at $1-2 \mathrm{mM}$ initial concentration and stored at $-15^{\circ} \mathrm{C}$ in the dark for no more than a month. Immediately before the experiment, the solutions were diluted to the desired concentration with water or the Muller-Hinton medium. The initial peptide concentration for testing of their hemolytic activity was $10 \mathrm{mM}$ in water.

Antimicrobial activity of the peptides. We used a suspension of overnight broth cultures, which was grown on a standard nutrient media. The number of microorganisms (titer) in the suspension was evaluated by the optical absorption at $595 \mathrm{~nm}$. To evaluate the antibacterial effect of the peptides, they were incubated with the cell cultures in 96-well culture plates. The overnight broth cultures were resuspended in the Muller-Hinton medium (the Saburo medium for C. albicans) and harvested until the number of microorganisms reached $\sim 5 \times 10^{5} \mathrm{CFU} / \mathrm{mL}$. The solutions of the peptides were introduced into the wells, followed by the addition of the cell suspension in a ratio of $1: 9(\mathrm{v} / \mathrm{v}$, the total volume of $200 \mu \mathrm{L})$. The final concentrations of the peptides were $0.3-100 \mu \mathrm{M}$. In the case of the negative control, the corresponding volume of the Muller-Hinton medium (the Saburo medium for C. albicans) was introduced instead of the tested peptide solution. In the case of the positive control, the corresponding volume of the $\mathrm{AgNO}_{3}$ or chlorhexidine solutions in appropriate dilutions at the final concentrations of $0.3-100 \mu \mathrm{M}$ were introduced instead of the peptide solution. The reaction mixtures were incubated for $24 \mathrm{~h}$ at $37^{\circ} \mathrm{C}$ on a shaker incubator (Kuhner LT-X, ABTEK, Russia) at $560 \mathrm{rpm}$. The optical absorption of the suspension was measured at $595 \mathrm{~nm}$ at regular intervals $(0,2,4,5,6,7,8$, and $24 \mathrm{~h})$ on a plate iMark ${ }^{\mathrm{TM}}$ spectrophotometer (BioRad, United States). The results were expressed as a mean value of the optical absorption of the cell suspension obtained in three independent experiments in two repeats. The average statistical error (standard deviation of the experimental values) did not exceed 15$30 \%$. The standard deviation (S) was calculated using the formula:

$$
S=\sqrt{\frac{1}{n}} \sum_{i=1}^{n}\left(x_{i}-x_{\mathrm{m}}\right)^{2}
$$

where $n$ is the number of measurements, $x_{i}$ is the $i$ th element of the data series, and $x_{\mathrm{m}}$ is the arithmetic mean of the data series.

Calculation of $\mathbf{M I C}_{50}$. The mean values of the optical absorption of cell culture suspensions were used to evaluate the values of the relative growth degree of microbe cultures $\left(N_{\mathrm{p}} / N_{0}\right)$ as the ratio of the optical absorption (concentration) of the microbial particles after the addition of the peptide preparation $\left(N_{\mathrm{p}}\right)$ to the optical absorption (concentration) in the control culture $\left(N_{0}\right)$. The peptide concentration, which led to $50 \%$ growth inhibition of the microbe cells, was evaluated by the dependence curves of $N_{\mathrm{p}} / N_{0}$ (in percentage) on the peptide concentration.

Photometric method of the evaluation of hemolytic activity of antimicrobial peptides against human erythrocytes. The hemolytic activity of the peptides was tested against fresh human red blood cells according to previously published methods $[6,28]$. The method is based on measuring the optical absorption at $540 \mathrm{~nm}$ in the supernatant liquid after centrifugation of a suspension of red blood cells. After destroying the red blood cells, hemoglobin releases from the cells, and the medium turns the characteristic red color, which persists after the precipitation of red blood cells. Fresh human erythrocytes were washed three times with PBS $\left(10 \mathrm{mM} \mathrm{Na} \mathrm{HPO}_{4}\right.$ and $1.76 \mathrm{mM} \mathrm{KH} \mathrm{PO}_{4}$, $\mathrm{pH}$ 7.4) that contained $173 \mathrm{mM} \mathrm{NaCl}$ and $2.7 \mathrm{mM}$ $\mathrm{KCl}$. The double serial dilutions of the peptide solutions were added to the erythrocyte suspension in PBS $(50 \mu \mathrm{L})$ to a final volume of $100 \mu \mathrm{L}$. The final erythrocyte concentration was $4 \%$ by volume (the volume of the suspension of the precipitated erythrocytes was taken as $100 \%$ ). The reaction mixture was incubated for $30 \mathrm{~min}$ at $37^{\circ} \mathrm{C}$. After centrifugation, the optical absorption of the supernatant was measured at $540 \mathrm{~nm}$. The optical absorption of the solution, which was obtained after the treatment of erythrocytes with $10 \%$ Triton X-100, was taken as $100 \%$. The optical absorption of the solution, which was obtained after the treatment of erythrocytes with a buffer solution without peptides, was taken as $0 \%$. The analysis of the hemolysis was performed two times using the same human blood sample. The data are presented as mean values \pm standard deviations of three independent experiments. The mean error of the experiment did not exceed $15-20 \%$. 


\section{CONCLUSIONS}

The synthesis of the cationic peptides with the general formula $\mathrm{X}_{9} \mathrm{Phe}_{2}$ where $\mathrm{X}$ is the arginine, lysine, or histidine residues occurs with approximately the same efficiency and is almost independent of their cationic composition:

$$
\mathbf{P} 3 \text {-His } \approx \mathbf{P} 1-\text { Arg } \approx \text { P2-Lys. }
$$

The replacement of the arginine residues by the lysine or histidine residues significantly reduces the antibacterial properties of SAMPs in a series:

$$
\text { P1-Arg > P2-Lys } \gg \text { P3-His, }
$$

i.e., the cationic SAMP analog, P1-Arg, exhibits maximal antibacterial activity $\left(\mathrm{MIC}_{50}=43-76 \mu \mathrm{M}\right)$, and peptide $\mathbf{P 3}$-His has almost no activity $\left(\mathrm{MIC}_{50}>100 \mu \mathrm{M}\right)$.

All peptides P1-Arg, P2-Lys, and P3-His exhibit 6-10 times higher activity against conditionally pathogenic yeast culture Candida albicans than against bacterial cultures. However, the order of effectiveness of the antifungal and antibacterial action of the peptides is completely different from the case of their effect on bacterial cell cultures. The efficiency of the peptides against the yeast $C$. albicans culture decreases in a series:

$$
\text { P3-His } \gg \text { P1-Arg }>\text { P2-Lys. }
$$

Considering the same efficiency of the synthesis and approximately the same low toxicity of the tested peptides, we recommend using SAMPs with a linear type of amphipathicity that contain the cationic arginine or histidine residues to create antibacterial or antifungal drugs, respectively.

\section{ACKNOWLEDGMENTS}

The strains of microorganisms were provided from the Collections of Extremophilic Microorganisms and Type Cultures (Institute of Chemical Biology and Fundamental Medicine, Siberian Branch, Russian Academy of Sciences).

\section{FUNDING}

The work was supported by the Program of Fundamental Scientific Research of the State Academies of Sciences on 2017-2020 (VI.62.1.4, 0309-2016-0004 and VI.55.1.1, 0309-2016-0002).

\section{COMPLIANCE WITH ETHICAL STANDARDS}

This article does not contain any studies with the use of animals as objects of research. All procedures involving humans (blood sampling for testing the hemolytic activity of drugs) comply with the ethical standards of the institutional and/or National Committee on Research Ethics, the Helsinki Declaration of 1964, and its subsequent amendments or comparable ethical standards. Voluntary consent was obtained from each of the participants included in the study.

\section{Conflict of Interests}

The authors state that there is no conflict of interests.

\section{OPEN ACCESS}

This article is licensed under a Creative Commons Attribution 4.0 International License, which permits use, sharing, adaptation, distribution and reproduction in any medium or format, as long as you give appropriate credit to the original author(s) and the source, provide a link to the Creative Commons licence, and indicate if changes were made. The images or other third party material in this article are included in the article's Creative Commons licence, unless indicated otherwise in a credit line to the material. If material is not included in the article's Creative Commons licence and your intended use is not permitted by statutory regulation or exceeds the permitted use, you will need to obtain permission directly from the copyright holder. To view a copy of this licence, visit http://creativecommons.org/licenses/by/4.0/.

\section{REFERENCES}

1. Peschel, A. and Sahl, H.G., Nat. Rev. Microbiol., 2006, vol. 4 , pp. 529-536. https://doi.org/10.1038/nrmicro1441

2. Bahar, A.A. and Ren, D., Pharmaceuticals (Basel), 2013, vol. 6, pp. 1543-1575. https://doi.org/10.3390/ph6121543

3. Chung, P.Y. and Khanum, R.J., Microbiol. Immunol. Infect., 2017, vol. 50, pp. 405-410. https://doi.org/10.1016/j.jmii.2016.12.005

4. Overton, K., Greer, H.M., Ferguson, M.A., Spain, E.M., Elmore, D.E., Nunez, M.E., and Volle, C.B., Langmuir, 2020, vol. 36, pp. 650-659. https://doi.org/10.1021/acs.langmuir.9b02726

5. Bílikova, K., Huang, S.C., Lin, I.P., Šimuth, J., and Peng, C.C., Peptides, 2015, vol. 68, pp. 190-196. https://doi.org/10.1016/j.peptides.2015.03.001

6. Panteleev, P.V., Bolosov, I.A., Balandin, S.V., and Ovchinnikova, T.V., J. Pept. Sci., 2015, vol. 21, pp. 105113. https://doi.org/10.1002/psc.2732

7. Vlieghe, P., Lisowski, V., Martinez, J., and Khrestchatisky, M., Drug Discov. Today, 2010, vol. 15, pp. 4056.

https://doi.org/10.1016/j.drudis.2009.10.009

8. Jiang, Z., Vasil, A.I., Hale, J.D., Hancock, R.E., Vasil, M.L., and Hodges, R.S., Biopolymers, 2008, vol. 90, pp. 369383.

https://doi.org/10.1002/bip.20911

9. Huang, Y.B., Huang, J.F., and Chen, Y.X., Protein Cell, 2010, vol. 1, pp. 143-152. https://doi.org/10.1007/s13238-010-0004-3

10. Bechinger, B. and Gorr, S.U., J. Dent. Res., 2017, vol. 96, pp. 254-260. https://doi.org/10.1177/0022034516679973

11. Matsuzaki, K., Sugishita, K., Harada, M., Fujii, N., and Miyajima, K., Biochim. Biophys. Acta, 1997, 
vol. 1327, pp. 119-130. https://doi.org/10.1016/s0005-2736(97)00051-5

12. Smirnova, M.P., Afonin, V.G., Shpen', V.M., Tyagotin, Yu.V., and Kolodkin, N.I., Russ. J. Bioorg. Chem., 2004, vol. 30, pp. 409-416. https://doi.org/10.1023/B:RUBI.0000043782.21640.c2

13. Amirkhanov, N.V., Tikunova, N.V., and Pyshnyi, D.V., Russ. J. Bioorg. Chem., 2018, vol. 44, pp. 492-503. https://doi.org/10.1134/S1068162018050035

14. Amirkhanov, N.V., Tikunova, N.V., and Pyshnyi, D.V., Russ. J. Bioorg. Chem., 2019, vol. 45, pp. 833-841. https://doi.org/10.1134/S1068162019060037

15. Chen, Y., Mant, C.T., Farmer, S.W., Hancock, R.E., Vasil, M.L., and Hodges, R.S., J. Biol. Chem., 2005, vol. 280, pp. 12316-12329. https://doi.org/10.1074/jbc.m413406200

16. Schiffer, M. and Edmundson, A.B., Biophys. J., 1967, vol. 7 , pp. 121-135.

17. Chan, W.C. and White, P.D., in Fmoc Solid Phase Peptide Synthesis: A Practical Approach, Chan, W.C. and White, P.D, Eds., Oxford: IRL Press, 2000, pp. 64-66.

18. Amirkhanov, N.V., Zhang, K., Aruva, M.R., Thakur, M.L., and Wickstrom, E., Bioconjug. Chem., 2010, vol. 21, pp. 731-740. https://doi.org/10.1021/bc900523c

19. Amirkhanov, N.V., Amirkhanov, R.N., and Zarytova, V.F., Russ. J. Bioorg. Chem., 2012, vol. 38, pp. 613-624. https://doi.org/10.1134/s1068162012060027

20. Khurshid, Z., Najeeb, S., Mali, M., Moin, S.F., Raza, S.Q., Zohaib, S., Sefat, F., and Zafar, M.S., Saudi Pharm. J., 2017, vol. 25, pp. 25-31. https://doi.org/10.1016/j.jsps.2016.04.027
21. Tsai, H. and Bobek, L.A., Biochim. Biophys. Acta, 1997, vol. 1336 , pp. $367-369$. https://doi.org/10.1016/s0304-4165(97)00076-7

22. Oppenheim, F.G., Xu, T., McMillian, F.M., Levitz, S.M., Diamond, R.D., Offner, G.D., and Troxler, R.F., J. Biol. Chem., 1988, vol. 263, pp. 7472-7477. https://doi.org/10.1016/S0021-9258(18)68522-9

23. Helmerhorst, E.J., Reijnders, I.M., Hof, W., SimoonsSmit, I., Veerman, E.C., and Amerongen, A.V., Antimicrob. Agents Chemother., 1999, vol. 43, pp. 702-704. https://doi.org/10.1128/aac.43.3.702

24. Xu, T., Levitz, S.M., Diamond, R.D., and Oppenheim, F.G., Infect. Immun., vol. 59, pp. 2549-2554. https://doi.org/10.1128/iai.59.8.2549-2554.1991

25. Lin, A.L., Shi, Q., Johnson, D.A., Patterson, T.F., Rinaldi, M.G., and Yeh, C.K., Clin. Diagn. Lab. Immunol., 1999, vol. 6, pp. 851-855.

26. Qin, Y., Zhang, L., Xu, Z., Zhang, J., Jiang, Y.Y., Cao, Y., and Yan, T., Virulence, 2016, vol. 7, pp. 512-526. https://doi.org/10.1080/21505594.2016.1138201

27. Puri, S. and Edgerton, M., Eukaryot. Cell, 2014, vol. 13, pp. 958-964. https://doi.org/10.1128/ec.00095-14

28. Jacobsen, F., Mohammadi-Tabrisi, A., Hirsch, T., Mittler, D., Mygind, P.H., Sonksen, C.P., Raventos, D., Kristensen, H.H., Gatermann, S., Lehnhardt, M., Daigeler, A., Steinau, H.U., and Steinstraesser, L., J. Antimicrob. Chemother., 2007, vol. 59, pp. 493-498. https://doi.org/10.1093/jac/dk1513

Translated by A. Levina 